\title{
MECHANICAL PROPERTIES AND FATIGUE LIFE DETECTION OF COPPER PARTICLE FILLED POLYESTER COMPOSITE MATERIAL UNDER ROTATING BENDING LOAD
}

\author{
Ahmed Fadhil HAMZAH ${ }^{1}$, Ali S. AL-TURAIHI ${ }^{2}$, Mustafa Baqir HUNAIN ${ }^{2}$, Essam Zuheir FADHEL ${ }^{2}$ \\ ${ }^{1}$ Department of Engineering of Polymer and Petrochemical Industries / Faculty of Materials Engineering / \\ University of Babylon \\ ${ }^{2}$ Mechanical Engineering Department / Faculty of Engineering / University of Babylon \\ * Corresponding Author, email: dr_m hunain@yahoo.com
}

\begin{abstract}
In the present investigation, the fatigue life detection of composite material by adding copper particle of about than $25 \mu \mathrm{m}$ diameter with 5, 10, $15 \%$ volume fraction, as a reinforcements into the unsaturated polyester polymer composite material on fatigue life detection of composite material were studied experimentally and numerically. Composites were made using hand lay-up technique and evaluated for mechanical and fatigue properties in accordance with ASTM standards. The experimental results of the tensile test showed that adding $15 \%$ of copper particle in unsaturated polyester gives maximum ultimate tensile stress. Fatigue tests including test rod specimens made of composite materials under completely reversed cyclic loading in a rotating cantilever reversed bending machine. It is found that, the fatigue life and fatigue strength increase with increasing in the copper percentage volume fraction in unsaturated polyester resin compared with pure polyester composites. The experimental work was compared with numerical work, which was done by using ANSYS/19 and good agreement has been found. The maximum overall difference between the experimental and numerical work was around $9 \%$.
\end{abstract}

Keywords: polymer matrix composite, particle copper reinforcement, tensile strength, fatigue.

\section{INTRODUCTION}

A composite material could be a combination of two materials with diverse chemical and physical properties. The combination of materials making a fabric, which is particular to do a specific work, which is lighter, stronger and safe to use. As well as, enhancing some mechanical characteristic of material such as stiffness and tensile strength. The preference of composite material comes from the enhancing of base material's properties and wide range of application in the industries [1].

A reinforcement composite could be a particle with various dimensions generally equal are called particulate strengthened composites. Particulate fillers utilized to enhance the performances at elevated temperature, reduce shrinkage, enhancing wear resistance and diminish grinding. The particles will carry the load with the matrix. A particulate reinforcement not generally leads to strengthen but enhance the stiffness [2]. Many researchers have been investigated the Mechanical behaviour of composite materials such as, Antunes F.V. et al [3] predicted the fatigue life of three particles polymer composites with various particles sizes and various filler volume fractions. The fracture mechanics approach was used to obtain stress intensity factor for central hole specimens and compare the theoretical and experiment result.
It has been found that the influence of initial crack greater than the influence of particles sizes. Basaran C. et al [4] studied experimentally the influence of interfacial bond strength between the polymer matrix and filler particles on fatigue strength life. A Brittle alumina trihydrate (ATH) was used as filler particles and poly-methyl methacrylate (PMMA) as polymer matrix. It has been found that the composite with lowest interfacial bonding strength had the better fatigue life. Swapan K. et al [5] investigated the mechanical characteristics of poly (vinyl chloride)-copper composites. It has been found that the strength properties were inverse proportional with particles contents. Garoushi S. et al [6] studied the compressive fatigue limits of resin/fiber reinforced composites. Three different types of fiber were used which are continuous unidirectional, bidirectional and short random fiber orientation. It has been found that material made of continuous bidirectional or particulate fiber composites and random fiber reinforced composites, obtain higher compressive fatigue limits than that acquired with plain particulate filler composite resin. Hyonny Kim et al [7] studied the fatigue mechanism of copper strips implanted into glass/epoxy. It was found that the fatigue crack growth coupled with de-bonding between the composite and the copper however, de-bonding preventing led to directly affect the fatigue 
behaviour of the implanted copper strip, much within the same way as composite patches hinder crack growth in repaired metal structures. Abdulsattar M. [8] examined the mechanical characteristics of polymer matrix composite strengthened by copper powder. It was found that the mechanical properties of composite were improved and friction coefficient of the composite material reduced. Al-Turaihi A. et al [9] investigated the fatigue life behaviour of polyester matrix reinforced with different volume fraction of chopped E-glass fiber numerically and experimentally. It has been found that the fatigue strength and the tensile were increased with volume fraction of fiber increasing. Hunain M. B. et al [10] investigated the effect of temperature on mechanical characteristics and failure mechanism of E-Glass-unsaturated polyester laminated composite material. It was found that there was an influence of temperature on mechanism of failure and the mechanical properties decreased with the increasing of temperature. Srivastava V. K. and Ansul Verma [11] investigated the mechanical properties of composite materials made of epoxy resin, copper and aluminum particles. It has been found that the wear and tensile strength were decreased with the increase of filler particles. Chan $\mathrm{K}$. L. et al [12] investigated the influence of adding silver and copper nanoparticles on electrical and thermal characteristics of epoxy composites. The result showed that the electrical and thermal properties were similar. Cheang P. and Khor K.A. [13] experimentally studied the influence of powder morophology on the mechanical characteristics of polymer-hydroxyapatite composites. The result showed that the tensile properties dependent on surface properties of the powder. Luyt A.S. et al [14] studied the electrical, mechanical and thermal characteristics of polyethylene filled with copper powder composites. The result showed that the electrical and thermal characteristics enhanced with adding copper powder while, the mechanical properties decreased compared with pure polyethylene matrix. Pargi et al [15] investigated the influence of mixed copper particle size filled epoxy composites on the thermal, electrical, and mechanical characteristics. The result showed enhancement in overall characteristics of epoxy composites filled with copper particles.

The literature review of this work is intended to give the reader a general understanding of mechanical properties, fatigue strength, of such composite materials. In this paper, the effect of volume fraction percentage (of about $25 \mu \mathrm{m}$ in diameter) of copper reinforcement with $(5 \%, 10 \%$ and $15 \%$ ) which filled an unsaturated polyester resin, on tensile modulus, tensile strength, and fatigue limit of composite material are studied experimentally and verified the fatigue behavior of such composite with the numerical simulation using the finite element technique by ANSYS workbench software program to have better understanding of mechanical properties of such composite materials.

\section{MATERIALS}

The materials used in preparing the samples consist of Unsaturated Polyester (UP), and copper particle as a reinforcement material. The Polyesters are perhaps the most widely used of the thermoset systems, accounting for about $75 \%$ of total resin usage. Polyester resins are classified as cheap and quick to use for low-cost applications. The copper particle with about $25 \mu \mathrm{m}$ in diameter used with (5, 10 and $15 \%$ ) volume fraction as a reinforcement material.

\section{EXPERIMENTAL PROCEDURE 3.1. Sample preparation}

The Hand lay-up technique has been used for the composites fabrication processes. The mold was cleaned, and suitable lubricant was used to cover the wall of the mold to avoid the adhesive between the specimens and the mold. The unsaturated polyester resin ("TOPAZ-1110 TP type") has been mixed with hardener MEKP, type ("Methyl Ethyl Keton Peroxide") in the ratio of $2 \%$ by weight [16] and with the reinforcement $\mathrm{Cu}$ particle in ratio of $(5,10$ and $15 \%)$ by volume.

The mold was placed in the vertical position to let the trapped air bubbles move toward the mold edge. The composite materials were kept in the mold for 24 hours to cure at room temperature, then the product of tensile and fatigue specimens were left in the oven at $70^{\circ} \mathrm{C}$ for 3 hours in order to achieve a sufficient curing process [17].

\subsection{Tensile specimen}

Tensile test was performed by using " $200 \mathrm{KN}$ WDW - 200 E III hydraulic test" machine, and constant strain rate of $2 \mathrm{~mm} / \mathrm{min}$. The samples were prepared according to ASTM D638 standard [18], as shown in figure 1. For more accuracy, three specimens of each material are tested, and then the average value of each case of composite materials is recorded.

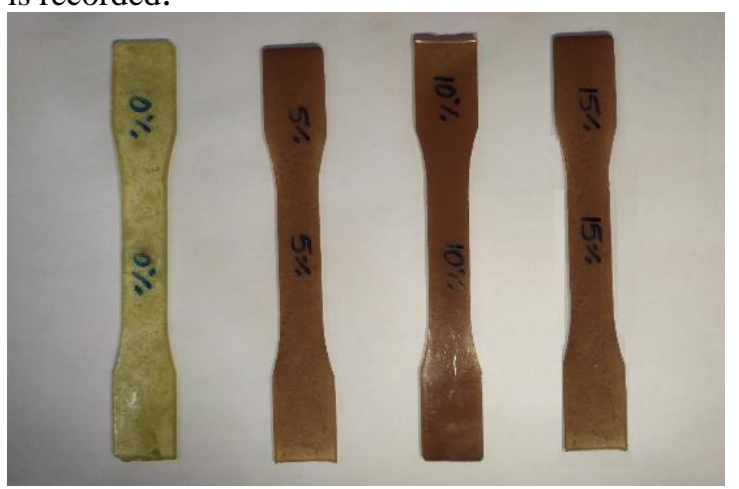

Fig. 1. Tensile test Specimens. 


\subsection{Fatigue test samples}

The fatigue test specimens were prepared in a dimension according to the specifications and requirements of the fatigue test machine with a cylindrical specimen. Figure 2 ( $a$ and $b$ ) shows the fatigue testing machine and the dimensions of the specimen. The fatigue specimen's prepared are shown in figure 3 , which are pure unsaturated polyester composites as well as polyester filled copper particles with a volume fraction of $(5,10$ and $15 \%$ ), respectively.

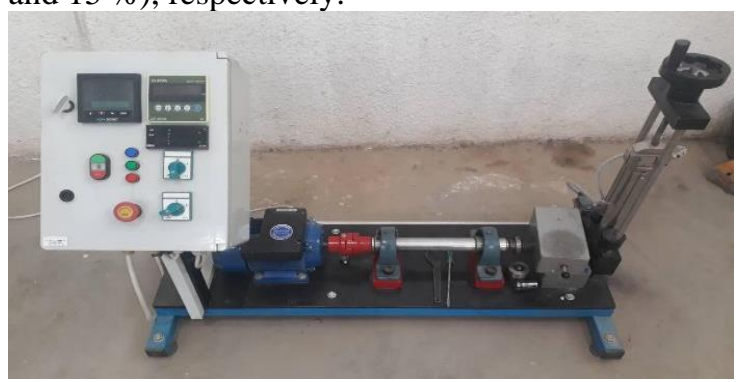

(a)

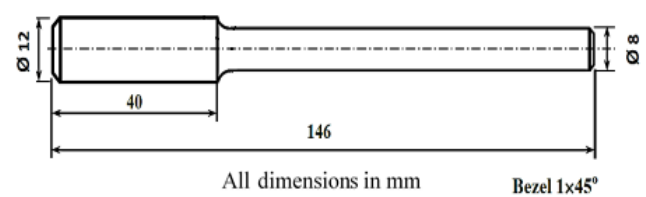

(b)

Fig. 2. Fatigue testing machine and Schematic diagram of test specimen according to ASTM specifications.

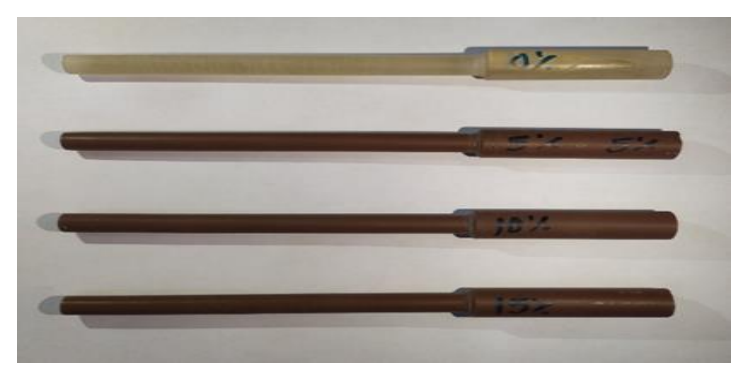

Fig. 3. Fatigue test specimen.

The fatigue-testing machine is fully rotating reversed bending, as cantilever with constant amplitude, with rotating speed 3000 r.p.m., voltage $220 \mathrm{~V}$, frequency $50 \mathrm{~Hz}$ and $0.5 \mathrm{HP}$ power capacity. The reversed stress amplitude is infinitely adjustable by the manual arm. A digital counter is used to display the cycles to failure under fatigue load. The maximum concentrated fatigue load is $(500 \mathrm{~N})$ can be applied on the free side of the specimen and the side of the specimen is clamped by the machine. The experiment was done by applied sinusoidal cyclic load and stress ratio $\mathrm{R}=-1$. Due to the alternating bending load, the cylindrical specimen after a certain number of cycles will fail as result of material fatigue phenomena. The rotating fatigue was performed by applying load on the opposite side perpendicular to the axis of the samples. The number of fatigue cycles is counted after failing the specimen with help of stopping sensor, which is causing shutdown of the testing machine. The experiment was performed by using seven specimens for each set with different applied load in each case and accounting the number of failed cycles to produce the $\mathrm{S}-\mathrm{N}$ for the experiment data.

The experiment bending moment was computed by multiplying the arm and the applied load as follows [19]:

$$
M=F . a
$$

The alternating stress amplitude can be calculated by using section modulus of the sample as follow:

$$
\sigma=\frac{M}{W}
$$

Where; $W=\frac{\pi d^{3}}{32}$

$$
\sigma=\frac{32 F \cdot a}{\pi d^{3}}
$$

Therefore, the alternating bending stress can be calculated from the following equation;

$$
\sigma \cong 2 F \quad(\mathrm{MPa})
$$

Where;

$\sigma$ : Maximum alternating bending stress $(\mathrm{MPa})$.

F: Experiment applied load (N).

a: Arm of bending $=106 \mathrm{~mm}$.

$\mathrm{d}$ : Specimen diameter $=8 \mathrm{~mm}$.

M: Bending moment (N.mm).

$\mathrm{W}$ : Section modulus of the specimen.

The S-N curve is a diagrammatic representation of the fatigue data. The analytical expression of S$\mathrm{N}$ curve was provided by using Basquin's equation. The simple form Basquin's equation is [20]:

$$
\sigma_{a}=a\left(N_{f}\right)^{b}
$$

Where $\sigma_{\mathrm{a}}$ is the stress amplitude in (MPa) and $N_{f}$ is the number of cycles to failure. The parameters a and $b$ are both constants, its values depends on the material and on the geometry, respectively. The fatigue life behaviour of material can be expressed by the power law equation as shown in table 2 .

\section{NUMERICAL PROCEDURE}

In the present work, ANSYS Workbench, a software program used in modeling fatigue test to estimate the fatigue life for each of the materials with volume fraction $(5,10,15 \%)$ as well as, pure polyester composites specimen under constant amplitude loading. A stress-life approach has been used to analysis the fatigue life of the material with assistance of ANSYS software as a numerical tool to explain the effect of Von Mises, max shear and max principal stresses based on the stress ratio $(\mathrm{R}=-$ 1). The simulation was done by using a brick solid element (SOLID186) in 3D modelling of solid 
structure, as default element, which exhibit quadratic displacement behaviour. [21].

In fatigue simulation, the number of failure cycles with applied stress on the specimen cannot predict mathematically, therefor the experimental data on the mechanical properties and fatigue test will be used. Then, the mesh step and the boundary conditions have applied to the geometry of test specimen. Finally, the fatigue tool has been used to find the safety factor, total deformation, maximum shear stress, equivalent stress, and life at different loads. The numerical fatigue analysis has been conducted under fully reversed bending with stress ratio $(\mathrm{R}=-1)$. Figure 4 presents the model that built which was simulating the same model used in the experimental work.

The meshing process has done by choosing the number of elements and the volume in each body. The automatic size control (Automatic mesh) has used to mesh the model as shown in figure 5. In the current work, the model modelled as a cantilever beam where it has fixed from one end and the applying load at the anther end, as shown in figure 6 .

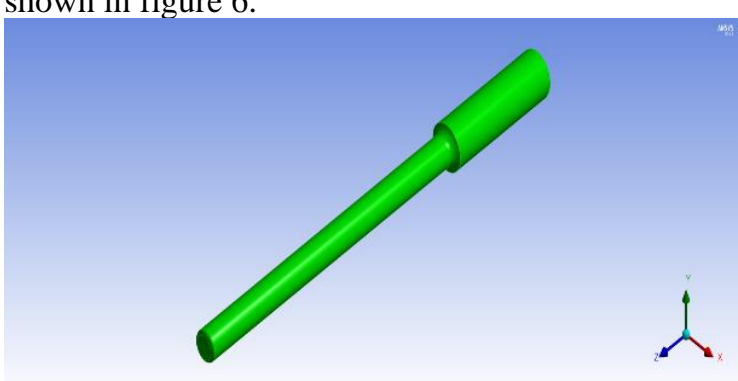

Fig. 4. Model of test specimen geometry of fatigue analysis.

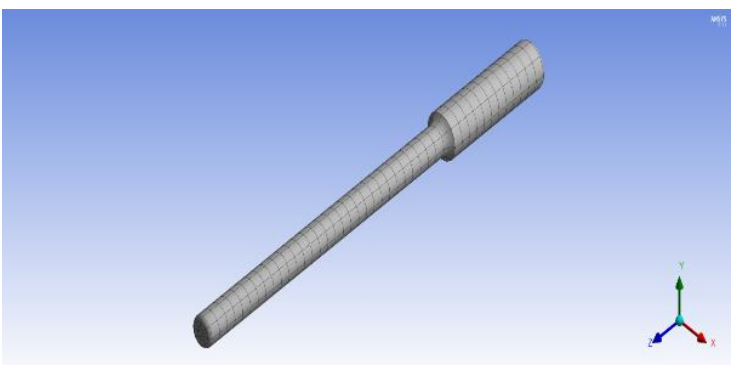

Fig. 5. The model with mesh.

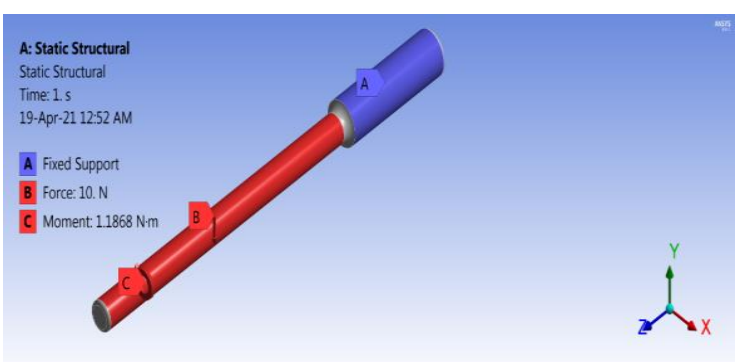

Fig. 6. The model with boundary condition.

\section{RESULTS AND DISCUSSION 5.1. Tensile properties}

The tensile test specimens have been installed in the universal tensile test machine and the test has been done. The test was repeated three times for all the tensile composite specimens then take the average value of the data. Tables 1 summarize the average values of the three measurement data results of the elastic modulus and tensile strength of the tested specimens respectively with its increment of volume fraction. Figure 7 shows the stress strain diagram, while figure 8 shows the influence of copper particle content into the max tensile strength, it can be noticed that the increase of the volume fraction of the composite will increase the tensile strength and elastic modulus. The addition of the particle contributes to strengthening of the composite, which cause failure retarding through the composite material and leads to decrease strain failure. The modulus of elasticity and maximum tensile strength of the composite is increased by 57 $\%$ and $31 \%$ respectively, when the volume fraction of $\mathrm{Cu}$ particle increased to $15 \%$ as compared with pure polyester.

Table 1. Tensile test results.

\begin{tabular}{|r|c|r|r|r|r|r|r|}
\hline \multicolumn{4}{|c|}{ Elastic modulus (GPa) } & \multicolumn{4}{|c|}{ Tensile strength (MPa) } \\
\hline Pure & $v_{f}=5$ & $v_{f}=10$ & $v_{f}=15$ & Pure & $v_{f}=5$ & $v_{f}=10$ & $v_{f}=15$ \\
UP & $\%$ & $\%$ & $\%$ & UP & $\%$ & $\%$ & $\%$ \\
\hline 3.65 & 5.82 & 7.31 & 8.57 & 35 & 39 & 45 & 51 \\
\hline
\end{tabular}

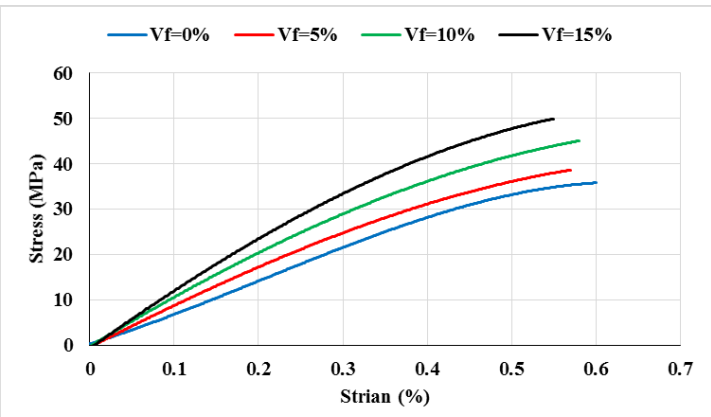

Fig. 7. Experimental stress strain diagram of unsaturated polyester filled $\mathrm{Cu}$ composites with Different volume fraction.

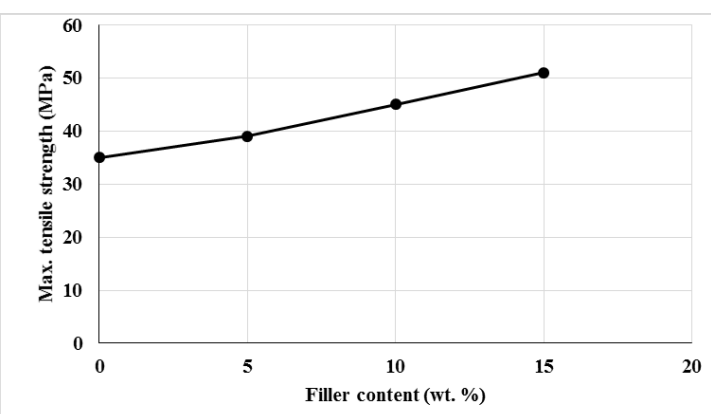

Fig. 8. Max tensile strength vs. $\mathrm{Cu}$ filler content diagram 


\subsection{Fatigue properties}

Many factors affect the fatigue performance ,such as the volume fraction of filler. The fatigue test was carried out for the pure unsaturated polyester and for the prepared composite materials, for each volume fraction (i.e. 5, 10 and $15 \%$ ), there are seven specimens were tested with different applied moments. Therefore, twenty-eight specimens were tested during the fatigue test and the results presented by $\mathrm{S}-\mathrm{N}$ curves. The curves are acquired by method of curve fitting. The power law equation constants, which show the fatigue life behaviour of the composite materials, can be seen in table 2 .

Table 2. Basquin's equations for current study of the experimental fatigue result.

\begin{tabular}{|c|r|}
\hline Volume fraction & Experimental \\
\hline Pure polyester & $\sigma_{f}=83.698 N_{f}^{-0.139}$ \\
\hline$v_{f}=5 \%$ & $\sigma_{f}=209.08 N_{f}^{-0.2}$ \\
\hline$v_{f}=10 \%$ & $\sigma_{f}=254.91 N_{f}^{-0.211}$ \\
\hline$v_{f}=15 \%$ & $\sigma_{f}=425.31 N_{f}^{-0.242}$ \\
\hline
\end{tabular}

In the first set of the experimental results which shown in figure 9. It can be observed that the fatigue life strength of the materials was decreased in various rates with the cycle number increasing. The decreasing happened rapidly in first hundred thousand cycles due the damage initiation and crack initiation in this region by fatigue. When the number of fatigue cycles increases, the decreasing in fatigue stress rate is changed and taken a new pattern, which is becoming less sharp than the first region. The new pattern of stress behaviour is approximately linear behaviour, which can be seen in between two readings of final failure. The particulate composite materials with a brittle matrix, like epoxy, the fatigue strength is widely depending on the initial size of crack. Therefore, these materials are sensitive to the site of crack initiation (e.g. fillers). As the particle volume fraction increases, the filler is more detrimental to overall fatigue strength. The linear behaviour of stress can be interpreted due to growing the crack and causing particle matrix de-bonding, following by area delamination, which is detectable, and then, the final failure or breakage of composite occurred. Figure 9 shows that the increase of volume fraction of $\mathrm{Cu}$ particle will increase the fatigue limit, its increasing by about $43 \%$ when filler content increase to $15 \%$.

The addition of the $\mathrm{Cu}$ filler contributes to strengthening of the composite that leads to impede the progress of the failure through the composite material. This is attributed to high modulus of elasticity, tensile strength, shear stress, and fracture toughness when increasing the volume fraction of the $\mathrm{Cu}$ particle.

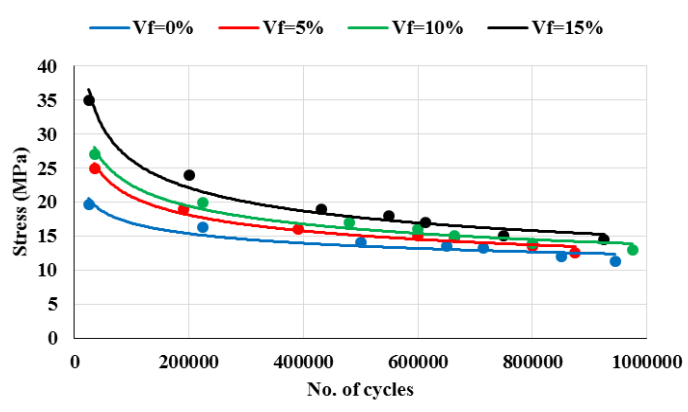

Fig. 9. Experimental S-N Curve of Cu particle filled UP composites with Different volume fraction.

The ANSYS/19 Workbench software package program used to study fatigue life strength of composite material numerically with various volume fraction, which are used in experimental work based on simple beam theory. A fully reversed load $(\mathrm{R}=-1)$ with constant amplitude was used to determine fatigue life. The numerical results compared with experimental results, as shown in figures 10, 11, 12, and 13. Numerical model using ANSYS package; where a specific moment is applied as cyclic load to find the amount of equivalent alternating stress resulting in the specimen. Equivalent alternating stress is the stress used to predict the fatigue $\mathrm{S}-\mathrm{N}$ curve with respect to many factors such as R-ratio and loading type. The moment of the experimental part was applied in numerical model by determining it using the simple theory of a cantilever beam (equation 1).

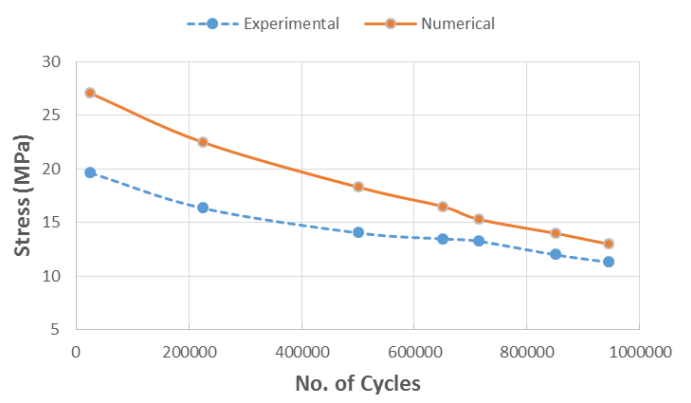

Fig.10. Comparison between experimental and numerical results for pure polyester specimen.

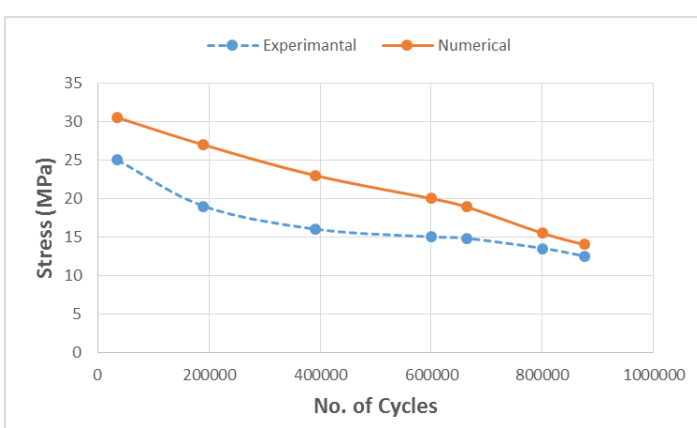

Fig.11. Comparison between experimental and numerical results for volume fraction of $5 \%$. 


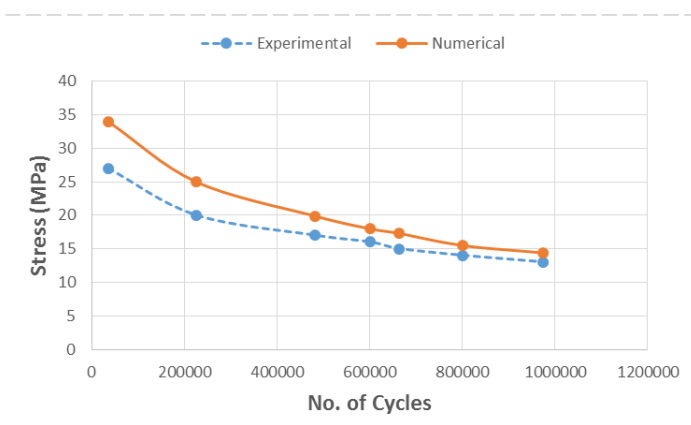

Fig. 12. Comparison between experimental and numerical results for volume fraction of $10 \%$.

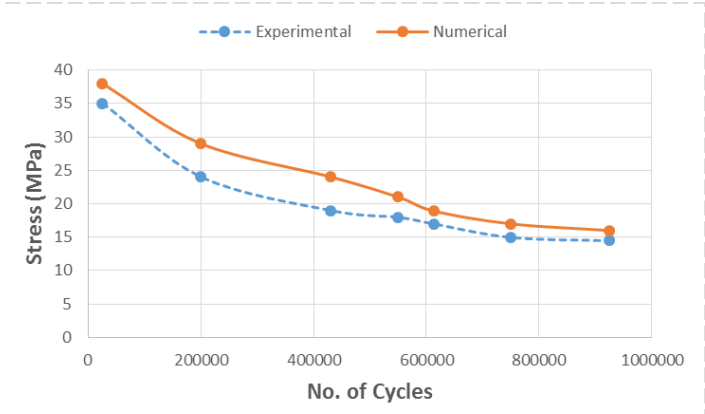

Fig. 13. Comparison between experimental and numerical results for volume fraction of $15 \%$.

Figure 14 shows contour plot of the available life for the given fatigue analysis for $\mathrm{Cu}$ particle filled polyester with volume fraction of $15 \%$. This figure represents the cycle's number until the component fail due to the fatigue at a constant amplitude loading. So it can be noted that the best life in the composite material with (15\%) of $\mathrm{Cu}$ filler, as shown in table 3 .

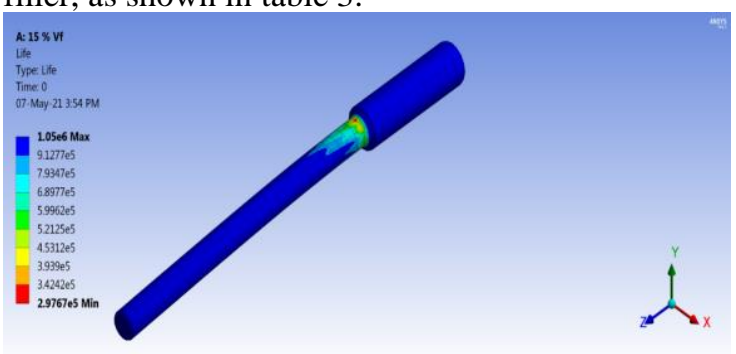

Fig. 14. Fatigue life analysis of $15 \% \mathrm{Cu}$ filled polyester composite.

Regarding to fatigue failure for the given design life, the maximum safety factor appeared is 15 as shown in figure 15 , like life and damage, this result may be watched. For safety factor of fatigue, the magnitude less than 1 means failure before the design life was reached. It can be noticed from table 3 that the material, which consists $15 \%$ of $\mathrm{Cu}$ filler has minimum safety factor 3.882, which is the best. Also, it can be noticed that the investigated materials with value of volume fraction are safe due to the magnitude of safety values are more than 1 which show that the failure will not occur during design life except the pure polyester where the minimum safety factor is $(0.417)$.

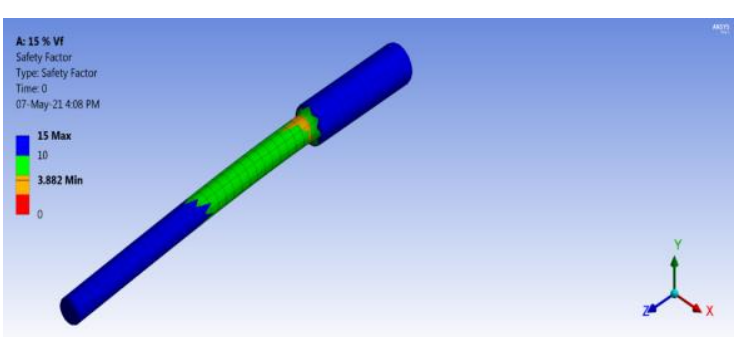

Fig.15. Safety factor of $15 \% \mathrm{Cu}$ filled polyester composite.

Figure 16 shows the maximum shear stress distribution throughout the specimen also, the value and location of maximum Shear stress. It can be noticed from the figure that the maximum value of maximum shear stress allocated in the contact area between the thin and wide part of the sample.

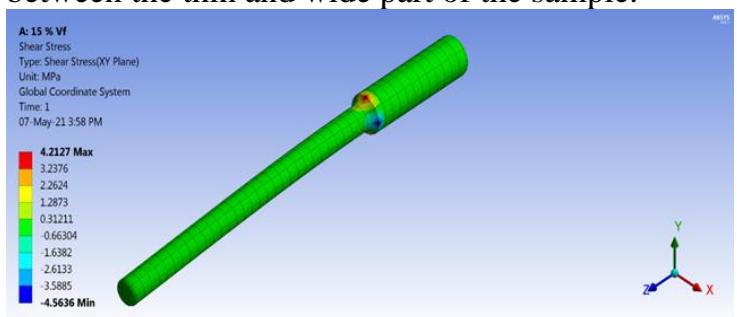

Fig. 16. Shear stress of $15 \% \mathrm{Cu}$ filled polyester composite.

Figure 17 shows an example for the Von-Mises stress produced in the model of $15 \% \mathrm{Cu}$ filled polyester composite. It can be noticed that the connection region between the specimen and the device has highest magnitude of equivalent VonMises stress because the reaction forces are high in the contact part and its normal behavior, which is a stress concentration region. It can be shown that the in the experimental side, applying the same value of moment was applied in numerical simulation by applying the deflection at the end of sample gradually from the extreme value down to the smallest value in excess then the number of cycle 106 cycles before fail. Sample may not fail when exceeded that number, where it is considered the value of stress at this point is the fatigue limit.

According to the Von-Mises theory, it can be noted that equivalent stress is less than the tensile stress of the composite as shown in table 3 , which will be safe in design because the minimum magnitude of equivalent Von Mises stresses which is obtaining a maximum structural strength. Also; it can be noted that the increase in the volume fraction in composite material will increase the value of the elastic properties of composite material and have effect on the final result of equivalent Von-Mises stress which can be seen, while the material with volume fraction (15\%) of glass fiber has minimum value of stress around (18.12 MPa). 


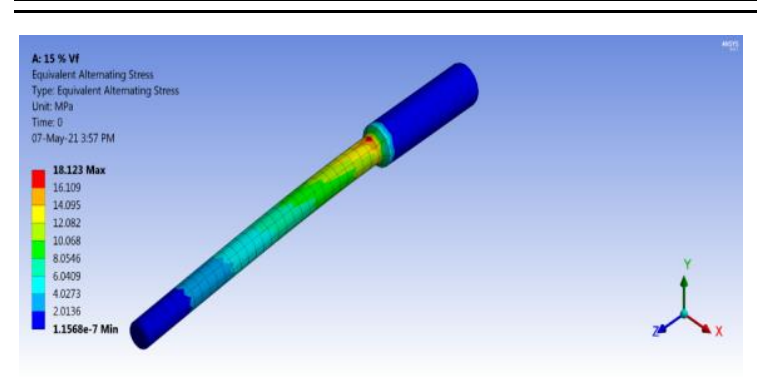

Fig.17. Equivalent Von-Mises stresses of $15 \% \mathrm{Cu}$ filled polyester composite.

Table 3 shows a summary of the results of the simulation part for fatigue testing for the composite materials used and for different volume fractions.

\begin{tabular}{|c|c|c|c|c|}
\hline $\begin{array}{r}\text { Volume } \\
\text { Fraction } \%\end{array}$ & Life (No) & $\begin{array}{l}\text { Min. } \\
\text { Safety } \\
\text { Factor }\end{array}$ & $\begin{array}{c}\text { Von- } \\
\text { Mises } \\
\text { Stress } \\
(\mathrm{MPa})\end{array}$ & $\begin{array}{l}\text { Shear } \\
\text { Stress } \\
(\mathrm{MPa})\end{array}$ \\
\hline $\begin{array}{c}\text { Pure } \\
\text { polyester } \\
\text { (UP) }\end{array}$ & 930000 & 0.417 & 27.09 & 5.33 \\
\hline 5 & 940000 & 1.93 & 23.76 & 5.12 \\
\hline 10 & 960000 & 2.76 & 20.34 & 4.67 \\
\hline 15 & 1050000 & 3.88 & 18.12 & 4.21 \\
\hline
\end{tabular}

\section{CONCLUSION}

The fatigue life and mechanical properties detection of copper particles reinforced polymer composite material behaviour has been done experimentally and numerically. The cupper particles have been used with different volume fraction $(5,10$, and $15 \%)$. In view of the results obtained, the following conclusions can be made from the present investigations:

1. Particular composite is an important type of composite materials, which can be used for manufacturing processes because of easy casting of different shapes.

2. The increasing of volume fraction of a copper powder to unsaturated polyester leads to increase in elastic modulus, tensile stress and ultimate tensile strength.

3. The fatigue strength of such composite increase when increased $\mathrm{Cu}$ particle as compared with that of pure polyester.

4. The fatigue life result shows success of all composite materials and the best magnitude of the safety factor is around 3.88 for the material contain $15 \%$ of $\mathrm{Cu}$ powder.

5. The equivalent Von-Mises stress is less than tensile stress of the composite, which will be safe in design for all composites.

6. The highest magnitudes of max shear stresses and equivalent Von-Mises are allocated in the connecting region of the sample with the device, which is the stress concentration region.

7. The experimental results are compared with numerical results and good agreement has been found with a maximum overall average difference of about $9 \%$.

\section{REFERENCES}

1. Bora B. Design and analysis filament wound composite tubes. m. sc thesis. Mechanical Engineering Department, The Graduate School of Natural and Applied Science. Middle East Technical university. 2004

2. Richardson T. Composites-a design guide. Industrial Press Inc. 200 Madison Avenue,Newyork. 1987.

3. Antunes FV, Ferreira JM, Costa JD, Capela C. Fatigue life predictions in polymer particle composites. International Journal of Fatigue 2002; 24: 1095-1105.

4. Basaran C, Nie S, Hutchins CS, Ergun H. Influence of interfacial bond strength on fatigue life and thermo-mechanical behavior of a particulate composite: an experimental study. International Journal of Damage Mechanics. 2008;17:123-147. http://dx.doi.org/10.1177/1056789507077437.

5. Swapan K. Bhattacharyya, Sadhan KD, Sanjay B. Studies on Poly(Viny1 Chloride)-Copper Composites. Part 1: State of Segregation of Filler Particles, Electrical and Mechanical Properties in Presence of Plasticizer and Stabilizer. Polymer Engineering And Science. 1979; 19(8): 533-539.

6. Sufyan Garoushi, Lippo VJ, Lassila, Arzu Tezvergil, Pekka K, Vallittu. Static and fatigue compression test for particulate filler composite resin with fiberreinforced composite substructure. Dental Materials. 2007; 23: 17-23.

7. Hyonny Kim, Myounggu Park, Kelli Hsieh. Fatigue fracture of embedded copper conductors in multifunctional composite structures. Composites Science and Technology. 2006; 66: 1010-1021.

8. Mohammed Abdulsattar Mohammed. Mechanical behavior for polymer matrix composite reinforced by copper powder. Nahrain University. College of Engineering Journal (NUCEJ). 2011; 14(2): 160-176.

9. Ali S. Al-Turaihi, Mustafa Baqir Hunain, Ahmed Fadhil Hamzah, Essam Zuheir Fadhel. Experimental and numerical investigation of fatigue behavior of chopped GFRP composite rod under rotating bending load. Journal of Mechanical Engineering Research and Developments. 2021; 44(2): 324-335.

10. Mustafa Baqir Hunain, Ali S. Al-Turaihi, Salah N. Alnomani. Tensile And Charpy Impact behavior of eglass / unsaturated polyester laminated composite material at elevated temperature. Journal of Engineering Science and Technology. 2021; 16(2): $1547-1560$

11. Srivastava VK, Verma A. Mechanical behaviour of copper and aluminium particles reinforced epoxy resin composites. American Journal of Materials Science. 2015;5(4):84-89. http://dx.doi.org/10.5923/j.materials.20150504.02.

12. Chan KL, Mariatti M, Lockman Z, Sim LC. Effects of the size and filler loading on the properties of copper-and silver-nanoparticle-filled epoxy composites. Journal of Applied Polymer Science. 2011;121:3145-3152. https://doi.org/10.1002/app.33798.

13. Cheang P, Khor KA. Effect of particulate morphology on the tensile behaviour of polymer/hydroxyapatite composites. Materials Science and Engineering A345. 2003; 47- 54. 
14. Luyt AS, Molefi JA, Krump H. Thermal, mechanical and electrical properties of copper powder filled lowdensity and linear low-density polyethylene composites. Polymer Degradation and Stability. 2006;91:1629-1636.

http://dx.doi.org/10.1016/j.polymdegradstab.2005.09.014.

15. Mohamad Nur Fuadi Pargi, Pei Leng Teh, Salmah Hussiensyah, Cheow Keat Yeoh and Supri Abd Ghani. Recycled-copper-filled epoxy composites: the effect of mixed particle size. International Journal of Mechanical and Materials Engineering. 2015;10(3): 1-10. http://dx.doi.org/10.1186/s40712-015-0030-2.

16. Quickmast 105 Data Sheet. http://www.depint.com.

17. Hayder MH. AL-Shukri. Experimental and Theoretical Investigation into Some Mechanical Properties of Glass Polyester Composite Under Static and Dynamic Loads. M.Sc thesis. Educational Technology/Mechanical Engineering Department, University of Technology, Baghdad, Iraq. 2007.

18. ASTM D638 / D638M-95. Standard specification for asbestos tubular sleeving. ASTM International, West Conshohocken, PA, 2017. http://www. astm.org.

19. GUNT. WP 140 Fatigue Testing Apparatus. Publication No.: 912.00000A 140 12. 2009. http://www.gunt.de.

20. Namik K. Alpaydin, Halit S. Turkmen. The Dynamic Response of the Sandwich Panel Subjected to the Impact Load. IEEE Xplore. 2009: 176-180. http://www.ivsl.org.

21. Abdul Jabar H. Ali, A non-linear damage model for fatigue life prediction of fiber reinforced polymer composite lamina at different temperatures. Ph.D. Theses, University of Technology. Mechanical Engineering Department. Baghdad. Iraq. 2013.

Received 2021-04-09

Accepted 2021-07-06

Available online 2021-08-13

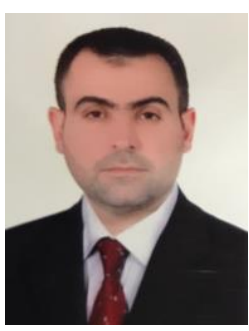

Ahmed Fadhil HAMZAH-

Assistant Professor at the University of Babylon in materials engineering filed, He got his B.Sc. degree in materials engineering in 2004, and received his M.Sc. in materials engineering also in 2007 from University of Babylon, and his Ph.D. in materials engineering (composite materials) in 2013 at University of Technology.

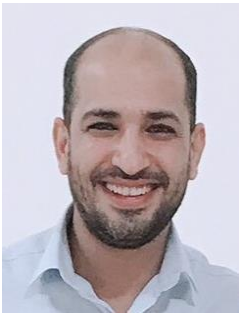

Ali S. AL-TURAIHI-Lecturer at Mechanical engineering department of Babylon university. He got his B. Sc degree in Mechanical engineering in 2005. He received his $M$. Tech in manufacturing engineering from NITK, surathkalIndia in 2011, and his $\mathrm{PhD}$ applied mechanical engineering from

Cranfield university- UK in 2017.

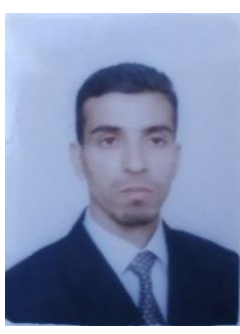

Mustafa Baqir HUNAINAssistant Professor at the mechanical engineering of the University of Babylon, $\mathrm{He}$ got his B. Sc. degree in mechanical engineering in 2004, He received his M. Sc. in mechanical engineering (Applied Mechanics) in 2007, and his Ph.D. in mechanical engineering (Applied Mechanics) in 2014.

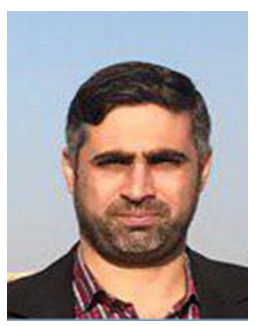

Essam Zuheir FADHEL-Assistant Professor at the mechanical engineering of the University of Babylon, He got his B. Sc. degree in mechanical engineering in 2004, $\mathrm{He}$ received his $M$. Sc. in mechanical engineering (Applied Mechanics) in 2007, and his Ph.D. in mechanical engineering (Applied

Mechanics) in 2015 